\title{
STUDI PENGARUH GEOMETRI LERENG PADA ANALISIS KEMANTAPAN LERENG 2D DAN 3D DENGAN METODE KESETIMBANGAN BATAS
}

\section{STUDY OF SLOPE GEOMETRY EFFECT ON 2D AND 3D SLOPE STABILITY ANALYSIS USING EQUILIBRIUM METHOD}

\author{
Muhammad Zaini Arief ${ }^{1 *}$, Nuhindro Priagung Widodo², Simon Heru Prassetyo ${ }^{3}$ \\ 1 Program Studi Rekayasa Pertambangan, Sekolah Pasca Sarjana, Bidang Khusus Geomekanika, Institut Teknologi \\ Bandung, Jl. Ganesha No. 10, Bandung, 40132, Indonesia \\ 2,3 Kelompok Keahlian Teknik Pertambangan, Fakultas Teknik Pertambangan dan Perminyakan, Institut Teknologi \\ Bandung, Jl. Ganesha No. 10, Bandung, 40132, Indonesia
}

Artikel masuk : 07-08-2020, Artikel diterima : 06-09-2020

Kata kunci:

Kestabilan Lereng, 2D \& 3D

Metode Kesetimbangan Batas,

Nikel

Keywords:

Slope Stability, Limit Equilibrium Method 2D \& 3D, Nickel

\begin{abstract}
ABSTRAK
Kestabilan suatu lereng umumnya dilakukan secara 2 dimensi (2D) karena dinilai lebih sederhana daripada 3 Dimensi (3D). Oleh karena itu, hanya sedikit analisis dilakukan secara 3D. Akan tetapi, jika dilihat dari asumsi lebar lereng analisis 2D dapat menjadi tidak representatif karena asumsi lebar lereng yang tak terbatas. Melalui analisis secara 3D hasil yang didapat lebih dapat dipercaya karena memperhitungkan batasan akhir lebar bidang longsor. Selain itu, volume dari potensi bidang longsor pun dapat diestimasi sehingga dapat digunakan sebagai bahan pertimbangan dalam pengambilan keputusan tindakan, selanjutnya sesuai dengan fungsi lereng. Hasil penelitian ini membuktikan lebar lereng 3D sangat berpengaruh terhadap geometri lereng 2D, dimana hasil Faktor Keamanan (FK) 2D baru hampir sama dengan FK 3D dapat diterima apabila rasio antara lebar $(\mathrm{W})$ dengan tinggi $(\mathrm{H})$ yaitu: tinggi $3 \mathrm{~m}$ dan 6 $\mathrm{m}$ rasio $\mathrm{W} / \mathrm{H}$ sebesar 3,3 , tinggi $12 \mathrm{~m}$ rasio $\mathrm{W} / \mathrm{H}$ sebesar 2,5 , dan tinggi $24 \mathrm{~m}$ rasio W/H sebesar 2,1 dengan material limonit, saprolit dan bedrock. Hasil FK 3D lebih besar dari FK 2D hal ini juga disebabkan oleh adanya pengaruh rasio lebar lereng dengan tinggi lereng. Dalam analisis $2 \mathrm{D}$, besar lebar lereng dianggap tidak terbatas (bidang lonsoran busur tidak terbatas), sedangkan dalam analisis 3D besar lebar lereng memiliki batasan (bidang longsoran berbentuk 1/4 bola). Dengan demikian hasil yang diperoleh pasti berbeda, baik besar nilai FK maupun lokasi bidang longsornya.
\end{abstract}

${ }^{*}$ Penulis Koresponden: zainiarief@gmail.com

Doi : https://doi.org/10.36986/impj.v2i1.27 


\section{ABSTRACT}

Slope stability analysis can be analyzed using $2 D$ because it is simpler than 3D analysis. Therefore, there are just a few cases that are done in $3 D$. However, if it is seen from its width of slope assumption, $2 D$ analysis can be unrepresentative because of the infinite width of the slope assumption. By analyzing a slope in $3 D$, the result can be more acceptable because it is considered the limit of the width of a failure. Moreover, the volume of failure can also be estimated so it can be used as a consideration in the decision making according to the slope function. The results of this study prove the width of the $3 D$ slope is very influential on the $2 D$ slope geometry, where the results of the new $2 D$ factor of safety (fos) are almost the same as the 3D fos can be accepted if the ratio between width $(\mathrm{w})$ and height $(\mathrm{h})$ is: for height $3 \mathrm{~m}$ and $6 \mathrm{~m}$ the $w / h$ ratio is 3,3 , for height $12 \mathrm{~m}$ the $w / \mathrm{h}$ ratio is 2,5 , and height $24 \mathrm{~m}$ the $\mathrm{w} / \mathrm{h}$ ratio is 2,1 with limonite, saprolite and bedrock material. The results of $3 d$ fos are greater than $2 d$ fos, this is also due to the influence of the ratio of the width of the slope to the height of the slope. In the $2 d$ analysis, the slope width is considered by infinite (infinite arc field), whereas in the $3 d$ analysis the slope width has a limit (landslide field in the form of 1/4 ball). Thus, the results obtained must be different, both the fos value and the location of the landslide field.

\section{PENDAHULUAN}

Dalam praktek penambangan tambang terbuka, penting untuk mengetahui seberapa stabilnya suatu lereng. Lereng merupakan faktor utama jalannya produksi suatu tambang. Suatu produksi tambang dapat berjalan dengan lancar karena lereng yang stabil. Kestabilan suatu lereng sangat bergantung pada karakteristik massa batuan serta kondisi dari faktorfaktor eksternal yang ada di lapangan seperti muka air tanah, getaran, dan lain-lain. Stabil tidaknya suatu lereng dapat diketahui dari nilai FK. Nilai FK suatu lereng dapat diketahui dengan analisis kestabilan lereng menggunakan metode tertentu.

PT $X$ melakukan penambangan di pit ABC. Desain lereng pit rencana sebelumnya telah dibuat terlebih dahulu. Untuk memastikan desain lereng tersebut aman maka perlu dilakukan analisis kestabilan lereng keseluruhan pit.

Berdasarkan penelitian-penelitian terdahulu, sering kali analisis kestabilan lereng dilakukan dalam 2D saja. Akan tetapi, jika dilihat dari asumsi lebar lereng, analisis 2D dapat menjadi tidak representatif karena asumsi lebar lereng tidak terbatas. Analisis kestabilan lereng yang dilakukan secara 3D tidak hanya dapat menentukan nilai FK yang representatif saja tetapi juga dapat diketahui besar estimasi volume suatu potensi longsoran. Setelah diketahui lokasi dan besar estimasi potensi longsoran maka dapat dilakukan langkah selanjutnya untuk memutuskan berdasarkan fungsi dari lereng di area tersebut.

\section{METODE}

Metode Bishop 3D dikembangkan berdasarkan ekstensi Metode 2D Bishop yang disederhanakan. Asumsi yang digunakan dalam metode ini yaitu bidang runtuh berbentuk bola dengan arah y dan z. Seluruh bidang runtuh telah didiskritisasi menjadi sejumlah kolom. Kondisi kesetimbangan yang dapat dipenuhi oleh metode ini adalah kesetimbangan gaya dalam arah vertikal untuk setiap kolom dan kesetimbangan momen pada pusat lingkaran runtuh untuk semua kolom, sedangkan kesetimbangan gaya dalam arah horisontal tidak dapat dipenuhi.

$N \operatorname{Cos} \theta_{z}+S_{m} \operatorname{Sin} \alpha-W=0$

Besarnya tahanan geser yang diperlukan agar lereng berada dalam kondisi tepat setimbang [Sm] dapat dinyatakan dengan persamaan sebagai berikut:

$S_{m}=\frac{\tau^{\prime} A}{F}=\frac{\left(c^{\prime}+\left(\sigma_{n}-u \tan \emptyset^{\prime}\right)\right) A}{F}=$ $\underline{c \prime A+(N-u A \tan \emptyset \prime)}$

Substitusi persamaan [2] ke persamaan [11] akan menghasilkan persamaan untuk gaya normal total $(\mathrm{N})$ sebagai berikut:

$N=\frac{W-\left(\frac{c^{\prime} A \operatorname{Sin} \alpha-u A \operatorname{Tan} \emptyset}{F}\right)}{\operatorname{Cos} \theta_{z}+\frac{\operatorname{Sin} \alpha \operatorname{Tan} \emptyset}{F}}$

W adalah berat total kolom, $u$ adalah tekanan air pori yang bekerja di tengah basis kolom, $\mathrm{C}$ adalah kohesi, $\varphi$ adalah sudut gesekan dalam, $A$ adalah area dasar dan $\mathrm{F}$ adalah faktor keamanan.

Hovland (1977) menurunkan area basis kolom, persamaan untuk area dasar $(A)$ sebagai berikut:

$A=b . d \frac{\sqrt{1-\sin ^{2} \alpha \sin ^{2} \beta}}{\operatorname{Cos} \alpha \cos \beta}$

Sudut $\theta_{z}$ antara arah gaya normal $N$ dan sumbu vertikal diperoleh dari geometri sebagai berikut:

$\theta_{z}=\cos ^{-1} \sqrt{\frac{1}{\tan ^{2} \alpha+\tan ^{2} \beta+1}}$

Kesetimbangan momen pada pusat lingkaran runtuh untuk semua kolom adalah sebagai berikut:

$\sum_{i=1}^{n}$ WRSin $\alpha-\sum_{i=1}^{n} S_{m} R=0 \ldots$

Dengan mensubstitusikan persamaan [2] ke dalam persamaan [6] akan menghasilkan persamaan untuk menghitung faktor keamanan $(F)$ sebagai berikut: 
$F=\frac{\sum_{i=1}^{n}\left[c^{\prime} A+(N-u A) \operatorname{Tan} \varnothing\right]}{\sum_{i=1}^{n} W \operatorname{Sin} \alpha}$

Analisis kestabilan lereng untuk menentukan Nilai FK 2D dan 3D dilakukan dengan menggunakan perangkat lunak Rocscience (Slide2 dan Slide3)

\section{DATA DAN HASIL ANALISA}

Data yang digunakan dalam analisis ini merupakan hasil uji laboratorium dari data geoteknik yang dilakukan oleh PT X melalui pengambilan conto inti batuan melalui pemboran geoteknik tahun 2012 dan tahun 2019 dilakukan juga penambahan sampel data geoteknik menggunakan shelby tube untuk lapisan limonit dan saprolit.

Agar mendapatkan distribusi material properties penyusun lereng maka dilakukan uji statistik menggunakan uji Kolmogorov-Smirnov (K-S) terhadap material properties yang didapat dari hasil uji laboratorium. Hasilnya material properties penyusun lereng dapat dilihat pada Tabel 1.

Tabel 1. Parameter Fisik dan Mekanik Material Penyusun Lereng Tunggal dan Keseluruhan

\begin{tabular}{|c|c|c|c|c|}
\hline No. & Litologi & $\begin{array}{c}\text { Densitas } \\
\left(\text { ton } / \mathrm{m}^{3}\right)\end{array}$ & $\begin{array}{c}\text { Kohesi } \\
(\mathrm{kPa})\end{array}$ & $\begin{array}{c}\text { Sudut Gesek } \\
\text { Dalam }\left({ }^{\circ}\right)\end{array}$ \\
\hline 1 & Limonit & 16.97 & 37.20 & 29.43 \\
\hline 2 & Saprolit & 15.93 & 32.66 & 28.19 \\
\hline 3 & Bedrock & 28.06 & 223.47 & 38.61 \\
\hline
\end{tabular}

Analisis kestabilan lereng tunggal dilakukan untuk setiap domain litologi dengan ketinggian jenjang $3 \mathrm{~m}, 6$ m, $12 \mathrm{~m}$, dan $24 \mathrm{~m}$, lebar $10 \mathrm{~m}, 20 \mathrm{~m}, 30 \mathrm{~m}, 40 \mathrm{~m}, 50$ $\mathrm{m}$, dan $60 \mathrm{~m}$, dengan variasi sudut $50^{\circ}, 60^{\circ}$, dan $70^{\circ}$.

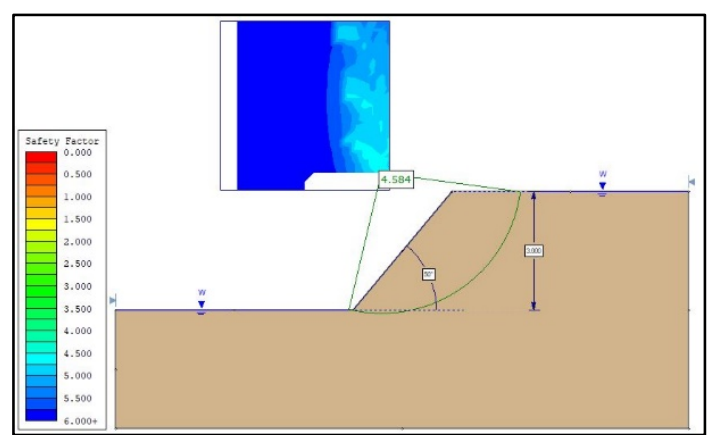

Gambar 1. Hasil Analisis Kestabilan Lereng 2D LEM

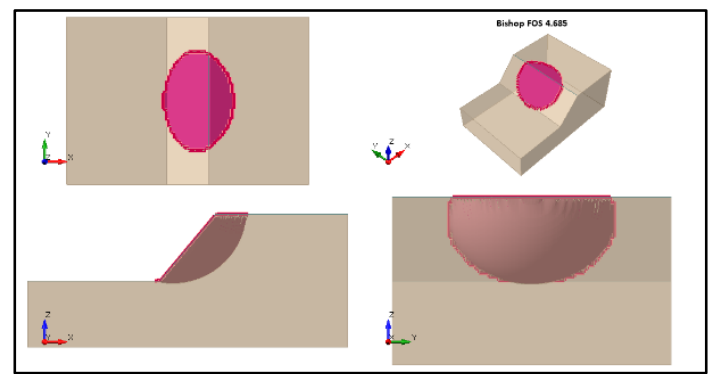

Gambar 2. Hasil Analisis Kestabilan Lereng 3D LEM

Berdasarkan hasil pemodelan lereng tunggal dapat dilihat perbedaan hasil FK dari geometri lereng 2D (panjang, tinggi dan sudut) terhadap lebar lereng 3D. Pada lereng tunggal tinggi $3 \mathrm{~m}$ sudut $50^{\circ}, 60^{\circ}, 70^{\circ}$ dengan lebar $10 \mathrm{~m}$ sampai dengan $60 \mathrm{~m}$ hasil FK 3D mendekati FK 2D. Pada lereng tunggal tinggi 6 m sudut $50^{\circ}, 60^{\circ}, 70^{\circ}$ dengan lebar $10 \mathrm{~m}$ hasil FK 3D lebih besar dari FK 2D, pada lebar $20 \mathrm{~m}$ sampai dengan $60 \mathrm{~m}$ hasil FK 3D mendekati FK 2D. Pada lereng tunggal tinggi 12 $\mathrm{m}$ sudut $50^{\circ}, 60^{\circ}, 70^{\circ}$ dengan lebar $10 \mathrm{~m}$ sampai dengan $20 \mathrm{~m}$ hasil FK 3D lebih besar dari FK 2D, pada lebar $30 \mathrm{~m}$ sampai dengan $60 \mathrm{~m}$ hasil FK 3D mendekati FK 2D. Pada lereng tunggal tinggi $24 \mathrm{~m}$ sudut $50^{\circ}, 60^{\circ}$, $70^{\circ}$ dengan lebar $10 \mathrm{~m}$ sampai dengan $40 \mathrm{~m}$ hasil FK 3D lebih besar dari FK 2D, pada lebar $50 \mathrm{~m}$ sampai dengan $60 \mathrm{~m}$ hasil FK 3D mendekati FK 2D.

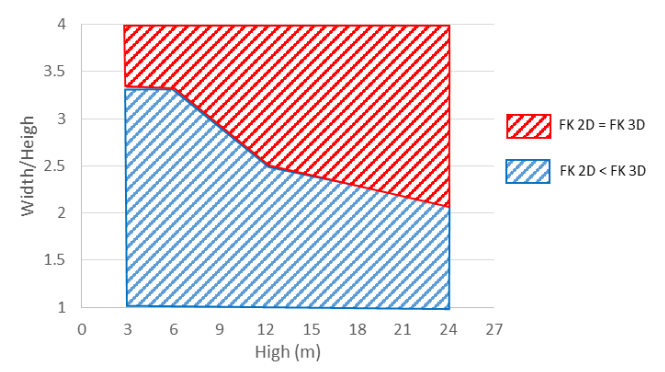

Gambar 3. Hasil Rasio Perbandingan Lebar Dengan Tinggi Lereng Terhadap Lereng Tunggal Yang Dianalisis 2D \& 3D

Dari hasil grafik di atas rasio untuk lebar (W) dengan tinggi $(\mathrm{H})$ untuk masing-masing lereng yaitu lebar $10 \mathrm{~m}$ dengan tinggi $3 \mathrm{~m}$ rasio $\mathrm{W} / \mathrm{H}$ sebesar 3,3. Pada lereng tunggal lebar $20 \mathrm{~m}$ dengan tinggi $6 \mathrm{~m}$ rasio $\mathrm{W} / \mathrm{H}$ sebesar 3,3. Pada lereng tunggal lebar $30 \mathrm{~m}$ dengan tinggi $12 \mathrm{~m}$ rasio $\mathrm{W} / \mathrm{H}$ sebesar 2,5. Pada lereng tunggal lebar $50 \mathrm{~m}$ dengan tinggi $24 \mathrm{~m}$ rasio W/H sebesar 2,08. Jadi, lebar lereng 3D sangat berpengaruh terhadap geometri lereng 2D berdasarkan hasil tersebut, hasil FK 3D baru hampir sama dengan FK 2D dengan rasio tertentu. Hasil analisis 2D dan 3D dapat dilihat pada Tabel 2. 


\begin{tabular}{|c|c|c|c|c|c|}
\hline \multirow[b]{2}{*}{ Material } & \multicolumn{2}{|c|}{ Geometri } & \multirow[b]{2}{*}{$\begin{array}{l}\text { FK } \\
2 D\end{array}$} & \multirow[b]{2}{*}{$\begin{array}{l}\text { FK } \\
\text { 3D }\end{array}$} & \multirow{2}{*}{$\begin{array}{c}\text { Rasio } \\
\text { FK } \\
\text { 3D/2D }\end{array}$} \\
\hline & $\begin{array}{l}\text { Tinggi } \\
\text { (m) }\end{array}$ & $\begin{array}{c}\text { Sudut } \\
\left(0^{\circ}\right)\end{array}$ & & & \\
\hline \multirow{12}{*}{ Limonit } & \multirow{3}{*}{3} & 50 & 4,58 & 4,69 & 1,02 \\
\hline & & 60 & 4,17 & 4,21 & 1,01 \\
\hline & & 70 & 3,76 & 3,97 & 1,06 \\
\hline & \multirow{3}{*}{6} & 50 & 2,47 & 2,56 & 1,04 \\
\hline & & 60 & 2,21 & 2,27 & 1,02 \\
\hline & & 70 & 2,03 & 2,17 & 1,07 \\
\hline & \multirow{3}{*}{12} & 50 & 1,40 & 1,48 & 1,05 \\
\hline & & 60 & 1,21 & 1,31 & 1,09 \\
\hline & & 70 & 1,19 & 1,23 & 1,04 \\
\hline & \multirow{3}{*}{24} & 50 & 0,83 & 0,89 & 1,07 \\
\hline & & 60 & 0,75 & 0,78 & 1,04 \\
\hline & & 70 & 0,73 & 0,77 & 1,06 \\
\hline \multirow{12}{*}{ Saprolit } & \multirow{3}{*}{3} & 50 & 4,25 & 4,30 & 1,01 \\
\hline & & 60 & 3,87 & 3,92 & 1,01 \\
\hline & & 70 & 3,48 & 3,69 & 1,06 \\
\hline & \multirow{3}{*}{6} & 50 & 2,27 & 2,35 & 1,03 \\
\hline & & 60 & 2,03 & 2,13 & 1,05 \\
\hline & & 70 & 1,86 & 2,01 & 1,08 \\
\hline & \multirow{3}{*}{12} & 50 & 1,28 & 1,34 & 1,05 \\
\hline & & 60 & 1,14 & 1,20 & 1,05 \\
\hline & & 70 & 1,07 & 1,14 & 1,06 \\
\hline & \multirow{3}{*}{24} & 50 & 0,77 & 0,80 & 1,03 \\
\hline & & 60 & 0,67 & 0,72 & 1,07 \\
\hline & & 70 & 0,65 & 0,70 & 1,08 \\
\hline \multirow{12}{*}{ Bedrock } & \multirow{3}{*}{3} & 50 & 16,29 & 17,05 & 1,05 \\
\hline & & 60 & 14,87 & 14,98 & 1,01 \\
\hline & & 70 & 13,37 & 13,80 & 1,03 \\
\hline & \multirow{3}{*}{6} & 50 & 8,59 & 9,13 & 1,06 \\
\hline & & 60 & 7,78 & 7,92 & 1,02 \\
\hline & & 70 & 6,98 & 7,23 & 1,04 \\
\hline & \multirow{3}{*}{12} & 50 & 4,72 & 5,09 & 1,08 \\
\hline & & 60 & 4,19 & 4,35 & 1,04 \\
\hline & & 70 & 3,82 & 4,00 & 1,05 \\
\hline & \multirow{3}{*}{24} & 50 & 2,76 & 2,98 & 1,08 \\
\hline & & 60 & 2,43 & 2,52 & 1,03 \\
\hline & & 70 & 2,29 & 2,32 & 1,01 \\
\hline \multicolumn{5}{|c|}{ Rata-rata } & 1,05 \\
\hline
\end{tabular}

Besar perbedaan rasio nilai $\mathrm{FK} 2 \mathrm{D}$ dan $3 \mathrm{D}$ secara keseluruhan dengan rata-rata sebesar sebesar 1,05. Hasil ini sama dengan penemuan dalam penelitianpenelitian terdahulu yang menyatakan FK 3D lebih besar dari FK 2D.

\section{STUDI KASUS}

Studi kasus ini diaplikasikan pada lereng keseluruhan pada tambang nikel PT X (Gambar 4). Dari gambar dapat terlihat bahwa lereng keseluruhan terdapat 3 domain yaitu limonit, saprolit, dan bedrock dengan geometri tinggi $24 \mathrm{~m}$, lebar $96 \mathrm{~m}$, dan sudut lereng keseluruhan adalah $47^{\circ}$.

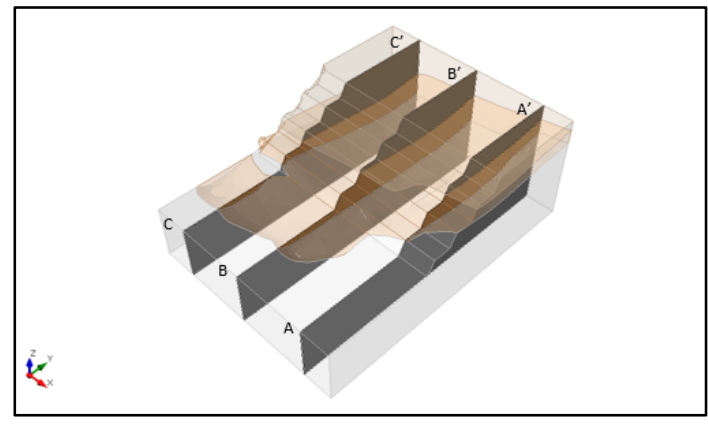

Gambar 4. Penampang Lereng Keseluruhan 3 Dimensi

Berdasarkan hasil analisis 3D dan 2D, pada kriteria Mohr-Coulomb maka dapat dinyatakan bahwa lereng dalam keadaan stabil, dinilai dari FK 3D 1,28. Estimasi volume potensi longsoran yang didapat yaitu 25.952 $\mathrm{m}^{3}$. Hasil FK 2D untuk section AA' yaitu sebesar 1,44, section BB' yaitu sebesar 1,25 , dan section $\mathrm{CC}^{\prime}$ yaitu sebesar 1,44. Lereng pada analisis 2D dalam keadaan stabil.

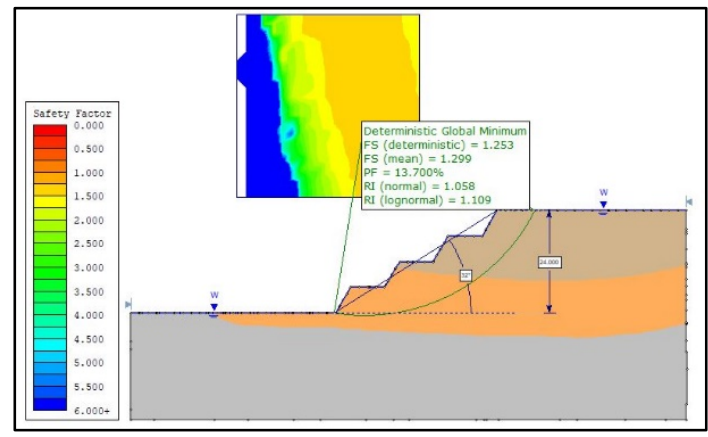

Gambar 5. Hasil Analisis Kestabilan Lereng 2D LEM Studi Kasus Tambang Nikel di PT. X

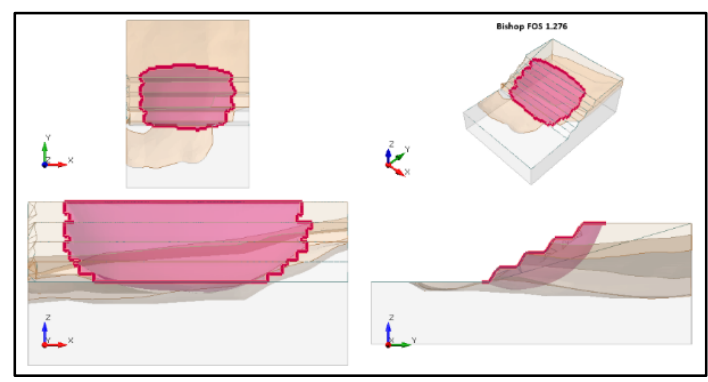

Gambar 6 Hasil Analisis Kestabilan Lereng 3D LEM Studi Kasus Tambang Nikel di PT. X

Hasil analisis $3 \mathrm{D}$ menghasilkan global minimum di bagian tengah lereng dengan FK 1,28. Hal ini sinkron dengan hasil analisis $2 \mathrm{D}$ menunjukkan bahwa section BB' (longsoran kritis 3D) memiliki nilai FK yang paling rendah diantara semua penampang yaitu dengan FK 1,25 . Hal ini berarti hasil analisis 3D tetap benar dan bahkan lebih dapat merepresentasikan lereng secara nyata.

Namun FK 3D lebih besar dari FK 2D hal ini disebabkan oleh adanya pengaruh rasio lebar lereng dengan tinggi lereng. Dalam analisis 2D, besar lebar lereng dianggap 
tidak terbatas, sedangkan dalam analisis 3D besar lebar lereng memiliki batasan. Oleh karena itu hasil yang diperoleh pasti berbeda, baik besar nilai FK maupun lokasi bidang longsornya.

Terlebih lagi ada pengaruh dari variasi dari model geologi. Analisis 2D menganggap tidak ada variasi model geologi sepanjang lereng, sedangkan dalam analisis 3D variasi model geologi tersebut tercakup. Oleh karena itu pasti ada perbedaan nilai FK antara analisis 2D dan 3D. Analisis 2D menjadi tidak representatif karena menganggap tidak ada variasi model geologi sepanjang lereng.

\section{KESIMPULAN}

Hasil penelitian lebar lereng 3D sangat berpengaruh terhadap geometri lereng 2D, Oleh karen itu, hasil FK 2D baru hampir sama dengan FK 3D dapat diterima apabila rasio lebar $(W)$ dengan tinggi $(H)$ sebagai berikut: tinggi $3 \mathrm{~m}$ dan $6 \mathrm{~m}$ rasio $\mathrm{W} / \mathrm{H}$ sebesar 3,3, tinggi $12 \mathrm{~m}$ rasio $\mathrm{W} / \mathrm{H}$ sebesar 2,5 , dan tinggi $24 \mathrm{~m}$ rasio $\mathrm{W} / \mathrm{H}$ sebesar 2,1 dengan material homogen limonit, saprolit, dan bedrock.

Hasil FK lereng tunggal dan studi kasus lereng keseluruhan 2D dan 3D untuk hasil FK yang didapatkan, FK 3D lebih besar dari FK 2D adapun hasil rasio $\mathrm{FK} 3 \mathrm{D} / 2 \mathrm{D}$ lereng tunggal secara keseluruhan dengan rata-rata FK 1,05, sedangkan lereng keseluruhan rasio nilai FK 1,02. Berdasarkan analisis 2D besar lebar lereng dianggap tidak terbatas (bidang lonsoran busur tidak terbatas), sedangkan dalam analisis 3D besar lebar lereng memiliki batasan (bidang longsoran berbentuk 1/4 bola). Dengan demikian hasil yang diperoleh pasti berbeda, baik besar nilai FK maupun lokasi bidang longsornya.

\section{UCAPAN TERIMA KASIH}

Penulis menyampaikan terima kasih yang sebesarbesarnya kepada Prodi S2 Rekayasa Pertambangan ITB, Laboratorium Mekanika Batuan yang telah memfasilitasi penulis dalam menggunakan perangkat lunak yang digunakan dalam permodelan data penelitian, dan kepada semua pihak yang terlibat dalam penelitian ini.

\section{DAFTAR PUSTAKA}

Akhtar, K. (2011): Three Dimensional Slope Stability Analyses For Natural and Manmade Slopes, Dissertation, University of Illinois.

Albataineh N. (2006): Slope Stability Analysis Using 2D and 3D Methods, Thesis, University of Akron.

Azizi, M. A. (2018): Three dimensional slope stability analysis of open pit limestone mine in Rembang District
Central Java, IOP Conference Series: Earth and Environmental Science.

Bishop, A. W. (1955): The use of the Slip Circle in the Stability Analysis of Slopes. Géotechnique, 5(1), 7-17.

Chakraborty, A., \& Goswami, D. (2018): Three-dimensional (3D) slope stability analysis using stability charts, International Journal of Geotechnical Engineering, 6362(May), 1-8.

Chakraborty, A., \& Goswami, D. (2016): Three Dimensional (3D) Slope-Stability Analysis, International Journal of Geotechnical Engineering, 10(5), 493-498.

Cheng, Y. M., \& Yip, C. J. (2007): Three-Dimensional Asymmetrical Slope Stability Analysis Extension of Bishop's, Janbu's, and Morgenstern-Price's Techniques, Journal of Geotechnical and Geoenvironmental Engineering, 133(12), 1544-1555.

Hovland. H.J. (1977): Three-dimensional slope stability analysis method, ASCE Journal of the Geotechnical Engineering Division. 103(GT9): 971-986.

Kalatehjari, R. \& Ali, N. (2013): A review of three-dimensional slope stability analyses based on limit equilibrium method, The Electronic Journal of Geotechnical Engineering, 2013 (18/A), 119-134.

Pyke, R. (2014): The Difference Between 2D and 3D Slope Stability Analyses. 4(1). Retrieved from https://tagasoft.com/wp-content/uploads/2017/06/3DEffects-in-Slope-Stability-Analyses.pdf

Reyes, A., \& Parra, D. (2014): 3D slope stability analysis by the using limit equilibrium method analysis of a mine waste dump, Proceedings Tailings and Mine Waste, Colorado, USA, 127-139.

Rocscience Inc., 2018. Slide v8.032 - Tutorial Manual. Rocscience Inc., Toronto.

Rocscience Inc., 2019. Slide3 v2019.015 - Tutorial Manual. Rocscience Inc., Toronto.

Stark, T. D., \& Eid, H. T. (2002): Performance of ThreeDimensional Slope Stability Methods in Practice. Journal of Geotechnical and Geoenvironmental Engineering, 124(11), 1049-1060.

Wyllie, D. C., \& Mah, C. (2004): Rock Slope Engineering, 4th edition, The Institute of Mining and Metallurgy, London, England, USA, Spoon Press Taylor \& Francis Group, 129-130.

Zhang, L., Fredlund, M. D., Fredlund, D. G., \& Lu, H. (2014). Comparison of 2-D and 3-D slope stability analyses for unsaturated soil slopes, Geo Regina 